\title{
A tragic death: a time to blame or a time to learn?
}

\section{W B Runciman, A Merry}

\section{A "just culture" is needed if patient safety is to be advanced.}

A teenage girl died earlier this year at Duke University Medical Center after a heart-lung transplant when the donor turned out to be $\mathrm{ABO}$ incompatible. ${ }^{1}$ The circumstances were particularly tragic and poignant; the funds for her procedure had been raised by concerned citizens in support of her desperate parents who had taken quite extraordinary steps to save the life of their daughter. The surgeon who requested and accepted the organs assumed that $\mathrm{ABO}$ compatibility had been established. The error was detected only after the procedure had been completed. In spite of every effort, life support had to be withdrawn some 2 weeks later when brain death became evident after a second transplant. The response of the hospital and its staff appears to have been exemplary. Responsibility for the disaster was accepted, everyone was kept fully informed, an urgent investigation was undertaken, and measures to prevent a recurrence immediately instituted. ${ }^{1}$ However, matters were made extraordinarily difficult for all involved, including her family, by an incendiary media frenzy.

In the short time since her tragic death there has been much comment on the events leading to it and on what is needed to prevent this happening again. ${ }^{1-3}$ But there are also crucial lessons to be learned from the way in which it has been reported and written about. These have wide implications. It would compound the tragedy if the "legacy" of this so public and so unnecessary death resulted in improvements in ensuring organ compatibility but also perpetuated attitudes that hinder significant advances in making health care safer. Five statements that appeared in just one paper illustrate how far we have to go to advance the understanding of safety within health care.

(1) "In the aftermath of such a disaster there must be an assignment of blame". Errors, by definition, are unintentional and are rarely truly blameworthy. ${ }^{4}$ Unfortunately, the tort system requires fault to be found and blame to be apportioned for compensation to be awarded, reinforcing the powerful human tendency to apportion blame on the basis of outcome rather than culpability. ${ }^{56}$ The assumption by the surgeon that incompatible organs would not have been offered was, in our view, reasonable, albeit disastrous in hindsight. Blamingand thereby effectively punishing-well intentioned individuals, whether team leaders or team members, when things go wrong as a result of genuine errors achieves nothing (as acknowledged by Campion $^{2}$ ), is unjust, and is usually counterproductive. ${ }^{7}$ Blaming and punishing is both reasonable and appropriate when a patient is harmed as a result of a violation or deliberately unsafe act, but this does not appear to have been the case here.

(2) "... last month the country heard that things at Duke had gone terribly wrong for no good reason". There are, in fact, excellent reasons why things go wrong with the present approach to trying to ensure ABO compatibility, whether for blood or for donor organs. ${ }^{89}$ It is currently inevitable that hundreds of $\mathrm{ABO}$ incompatibilities slip through the net every year, a substantial number of which result in death. Common errors such as misidentification and mislabelling at ward level, both at the time of taking blood samples and of giving blood (or tissue) can only be truly minimised by the establishment of a completely separate duplicate process, rather than trying to strengthen intrinsically vulnerable links in a single linear chain.

(3) "I am ultimately responsible for the team and for this error". We suggest that this traditional notion is anachronistic and illogical. While someone must be ultimately responsible for the overall structure and function of any team, this person cannot in reason or justice be responsible for every error made by any member of the team. Transplant surgeons have numerous important tasks to undertake under severe time constraints and it is inappropriate for them to have to divert their finite cognitive resource to ensuring that they personally check every aspect of every process. They should be entitled to rely on other trained professionals to do their jobs properly. Is it reasonable to hold the surgeon responsible if faulty filters or membranes were used in the cardiopulmonary bypass machine, or if a wrong drug was inadvertently used by the anesthesiologist? The problem in this case appears to have been a system failure and it is far from clear that any individual on the transplant team was "to blame". ${ }^{7}$ The processes used were simply inadequate and, unfortunately, this only became apparent by way of a disaster.

(4) "Her story does not support the cause of strict limits on the damages a jury can award". Whilst fully acknowledging the exceptional circumstances of this case and the inability of anyone bar her parents to fully appreciate the depth of the resulting grief and devastation, the general thrust of an argument to cap punitive damages should not logically be constrained by the story surrounding her death, however tragic and poignant. If anything, cases such as these provide a strong argument for capping punitive damages-which should only be awarded where genuinely culpable behaviour has occurred. Compensation for loss of earnings is a quite different matter, but probably does not apply to any significant extent in this case.

(5) "Nationally, this tragedy has already weakened the prospects in Congress for malpractice-liability reform". While this may be the case, it is at least partially because sensationalist media reports promote the unfettered advancement of popular misconceptions about the relationship between error and blame, especially when things that go wrong result in unexpected catastrophic outcomes. Accepting these misconceptions as the basis for what should ensue in the aftermath of a disaster such as this will simply result in "more of the same". While some may consider that editors in the populist press have a duty to reinforce the prejudices of their readers, we would argue that the opposite should pertain with respect to the mainstream medical press, which should promote a proper understanding of the complex relationships between error, blame, and violations when complex systems fail.

Major initiatives are underway to address the root causes of iatrogenic harm. One important aim is to replace the pervasive "blame culture" in health care with a "just culture" ${ }^{7}$ It behoves a journal with a richly deserved reputation for being at the forefront of disseminating research to act as a platform for advancing the complex arguments that must underpin initiatives in the area of patient safety. The statements we have commented upon reflect widely held sentiments. However, we believe that they are not in accordance with current thinking about organisational failure. ${ }^{467}$ Unchallenged, when presented in a leading medical journal, they will perpetuate one of the root causes of iatrogenic harm - the blaming of individuals for the tragic consequences of system failures.

Qual Saf Health Care 2003;12:321-322 


\section{A..................}

W B Runciman, Professor and Head, Department of Anaesthesia and Intensive Care, Royal Adelaide Hospital and University of Adelaide, South Australia; and President, Australian Patient Safety Foundation A Merry, Professor of Anaesthesiology, University of Auckland, Auckland, New Zealand

Correspondence to: Professor W B Runciman, Department of Anaesthesia and Intensive Care, Royal Adelaide Hospital, North Terrace, Adelaide, SA 5000, Australia; wrunciman@bigpond.com

\section{REFERENCES}

1 Molter J. Chronology of events regarding Jesica Santillan. Duke University Medical Center News. Available at http://news.mc.duke.edu/news/ article.php?id=6422 (accessed 8 May 2003)

2 Campion EW. A death at Duke. N Engl J Med 2003:348: 1083-4.

3 Selbst SM. The difficult duty of disclosing medical errors. Contemp Pediatr 2003;20:51-3.

4 Runciman WB, Merry AF, Tito F. Error, blame and the law in healthcare-an Antipodean perspective. Ann Intern Med 2003:138:974-9.

5 Caplan RA, Posner KL, Cheney FW. Effect of outcome on physician judgments of appropriateness of care. JAMA 1991;265: 1957-60.

6 Merry A, McCall Smith A. Errors, medicine and the law. Cambridge: Cambridge University Press, 2001.

7 Reason J. Managing the risks of

organisational accidents. Aldershot: Ashgate, 1997.

8 Linden JV, Wagner K, Voytovich AE, et al. Transfusion errors in New York State: an analysis of 10 years' experience. Transfusion 2000;40:1207-13.

9 The Serious Hazards of Transfusion Steering Group. Serious Hazards of Transfusion. Annual Report 2000-2001. Aransfusion. Annual Report 2000-2001. toc.htm (accessed 8 May 2003).
- focus on action;

- be prepared to learn from mistakes rather than punish them;

- work cooperatively; and

- measure what matters.

A core theme that underpins all these messages is the importance of a culture that is committed to improving performance and that values action as well as understanding. Health care has a mixed record in this respect. It is not short on knowledge and it is not lacking in action; the challenge for those trying to improve performance is to increase the linkages between the two.

There are some astonishing examples of slowness to implement knowledge even when the benefits for patients and the healthcare system are clear. Handwashing is a simple, virtually risk free action that helps prevent hospital acquired infection-a condition that carries substantial mortality, morbidity and cost. ${ }^{8}$ The benefits of handwashing have been repeatedly demonstrated over the past 150 years. ${ }^{9}$ Yet healthcare workers in general do not wash their hands; a review of 11 studies published in 2000 noted that the level of compliance with basic handwashing ranged from $16 \%$ to $81 \%{ }^{10}$ The barriers to uptake have been clearly described ${ }^{11}$ but, in most cases, the system appears paralysed in terms of its ability to take effective action. A compelling external threat can bring sudden change; it took little more than 2 weeks after the first patient with a case of severe acute respiratory syndrome (SARS) was admitted to Mount Sinai Hospital in Toronto for frequent handwashing to become an institutional requirement, ${ }^{12}$ but it is unlikely that these measures will spread to areas where SARS is unknown.

In contrast, there are several other areas in health care that have been characterised by rapid diffusion of innovation; countless new technologies have been embraced with a passionate zeal resulting in widespread uptake. The problem is that rapid uptake is not necessarily linked to good evidence. There are many instances where unwarranted enthusiastic adoption of unproven 
technology-“fashions" in operations and drug use-or behaviours such as bottle feeding instead of breast feeding has led to harm. ${ }^{13}$ Twenty years ago McKinley mapped the career of a medical innovation $^{14}$ and advocated for policy makers to use evidence of effectiveness in decisions about allocation of healthcare resources. We still have a lot to learn about how to harness individual and organisational enthusiasm for adopting innovation and to direct this energy into areas where there is sound evidence of value to be gained from increased uptake.

Making better connections between knowledge generation, knowledge delivery, and practical action is the challenge that now faces the healthcare industry if it wants to improve performance and deliver better care. Our efforts this century should focus on designing the can and the can opener in parallel.

Qual Saf Health Care 2003;12:322-323

\section{Author's affiliation}

H Buchan, Chief Executive Officer, National Institute of Clinical Studies, PO Box 6532, St Kilda Road Central, Melbourne, Victoria 3004 Australia; ceo@nicsl.com.au

The National Institute of Clinical Studies is Australia's national agency for improving health care by helping close gaps between best available evidence and current clinical practice.

\section{REFERENCES}

1 Panati C. Panati's extraordinary origins of everyday things. Harper \& Row, 1989

2 Davidoff F, Haynes B, Sackett D, et al. Evidence-based medicine: a new journal to help doctors identify the information they need. BM 1995:310:1085-6.

3 The Cochrane Library (database on disk and CD ROM). Cochrane Collaboration. Oxford: Update Software; 2003 (updated quarterly).

4 Evidence Based Medicine. London: BM Publishing Group, 2003.

$5 \mathrm{http}: / /$ clinicalevidence.com

6 Gray JAM. Where's the chief knowledge officer? BM 1998;317:832-40.
7 Pfeffer J, Sutton RI. The knowing-doing gap: how smart companies turn knowledge into action. Boston, Mass: Harvard Business School Press, 2000.

8 Lautenbach E. Practices to improve handwashing compliance. In: Making health care safer: a critical analysis of patient safety practices. Evidence Report/Technology Assessment No 43. Agency for Healthcare Research and Quality, USA, 2001, chapter 12.

9 Handwashing Liaison Group. Hand washing: a modest measure with big effects. BM 1999;318:686.

10 Pittet D. Improving compliance with hand hygiene in hospitals. Infect Control Hosp Epidemiol 2000;21:381-6.

11 Grol R. Personal paper: beliefs and evidence in changing clinical practice. $B M$ 1997;315:418-21.

12 Maunder R, Hunter J, Vincent L, et al. The immediate psychological and occupational impact of the 2003 SARS outbreak in a teaching hospital. Can Med Assoc J 2003; 168: 1245-51

13 Grimes DA. Technology follies: the uncritical acceptance of medical innovation. JAMA 1993;269:3030-3.

14 McKinlay JB. From "promising report" to "standard procedure": seven stages in the career of a medical innovation. Milbank Quarterly 1981;59:374-411.

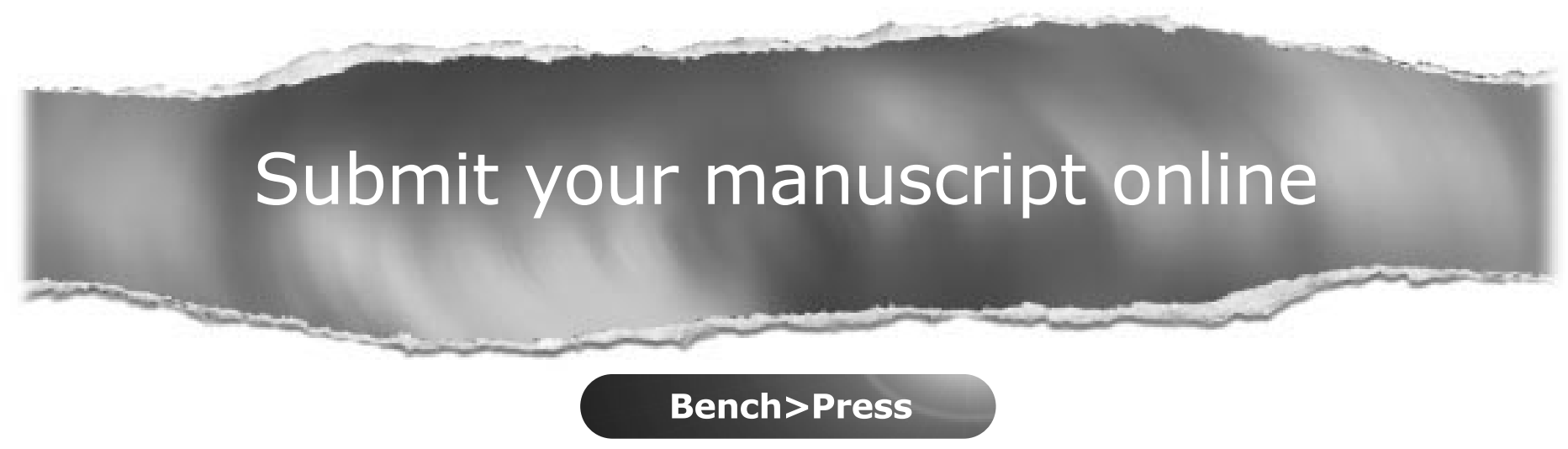

Click on 'submit/review a manuscript online' on our homepage to access Bench $>$ Press, our online submission and review system. Bench>Press enables the full peer review process to be conducted entirely online.

\section{www.qshc.com}

